\title{
DETERMINING THE FACTORS CAUSING HUMAN ERROR DEFICIENCIES AT A PUBLIC UTILITY COMPANY
}

\author{
FW BADENHORST \\ J VAN TONDER \\ Department of Human Resources Management \\ Rand Afrikaans University
}

\begin{abstract}
According to Neff (1977), as cited by Bergh (1995), the westernised culture considers work important for industrial mental health. Most individuals experience work positively, which creates a positive attitude. Should this positive attitude be inhibited, workers could lose concentration and become bored, potentially resulting in some form of human error. The aim of this research was to determine the factors responsible for human error events, which lead to power supply failures at Eskom power stations. Proposals were made for the reduction of these contributing factors towards improving plant performance. The target population was 700 panel operators in Eskom's Power Generation Group. The results showed that factors leading to human error can be reduced or even eliminated.
\end{abstract}

\section{OPSOMMING}

Neff (1977) soos aangehaal deur Bergh (1995), skryf dat in die westerse kultuur werk belangrik vir bedryfsgeestesgesondheid is. Die meeste persone ervaar werk as positief, wat 'n positiewe gesindheid kweek. Indien hierdie positiewe gesindheid geïnhibeer word, kan dit lei tot 'n gebrek aan konsentrasie by die werkers. Werkers kan verveeld raak en dit kan weer lei tot menslike foute. Die doel van hierdie navorsing is om die faktore vas te stel wat tot menslike foute lei, en wat bydra tot onderbrekings in kragvoorsiening by Eskom kragstasies. Voorstelle is gemaak vir die vermindering van hierdie bydraende faktore ten einde die kragaanleg se prestasie te verbeter. Die teiken-populasie was 700 paneel-operateurs in die Kragopwekkingsgroep by Eskom. Die resultate dui daarop dat die faktore wat aanleiding gee tot menslike foute wel verminder, of geëlimineer kan word.

According to Dhillon (1986), human error is the failure to carry out a specific task (or the performance of a forbidden action) that could lead to disruption of scheduled operations or result in damage to property and equipment. Performance target results are achieved through behaviour of the people performing the tasks. If the behaviour does not achieve its desired goal it is termed human error. It is an action that unintentionally departs from expected behaviour associated with some set standard (Mager \& Pipe 1992). In the power generation industry, electricity is produced at power stations by production plants called generating units. Loss in plant production occurs when there is an Unintentional Automatic Grid Separation (UAGS) or, in laymen terms, "a unit tripped" and when a generator is unable to produce electricity. When this UAGS is a result of human intervention, such as the departure from following correct operating procedures, it is termed a human error.

\section{Effects of human error}

When there is an interruption in the production line, it not only institutes a loss of income to the business unit, but also leads to an interrupted supply of electricity to the end-user customer. Other costs are the loss of revenue (income) to the business unit accompanied by expenditure such as overtime, as well as emotional stress (guilt feelings and feelings of failure) to the person/s responsible for the error.

The high profile of such incidents affects the person/s responsible for the tripping of the unit, who experience this as extremely negative, with corresponding negative effects on his/her quality of work life. Because of the interaction between an organisation and the sociopsychological environment of the individual, this negativism is bound to affect the employee's social support mechanisms such as his immediate family members (spouse/ children). Stressful work situations are bound to have an impact on family members.

Requests for copies should be addressed to: FW Badenhorst, Department of

Human Resource Management, RAU University, PO Box 524, Auckland Park, 2006
According to Reason (1990), researchers had concentrated on the hypothesis that reduction in human error would lead to improvement in human performance. Improved human performance promotes behaviours throughout an organisation that supports the reliable operation of the plant. A working environment should be created where all obstacles to excellent human performance are eliminated. This situation would reduce or even eliminate plant incidents caused by human error. Reduced production loss would result in improved productivity as well as higher income for the organisation and would also benefit the end-user customer by possibly fewer increases in the electricity price.

Reason (1990) found that human error occurs because human behaviour is fallible and can be caused by lack of concentration, not being motivated, ergonomic factors and various psychological and physical factors. It is possible to address these factors in the quest to improve human performance.

Human performance is defined as a series of behaviours executed to accomplish specific task objectives (results). Where human performance is below standard, it will inevitably lead to sub-standard performance by the production plant, as machines (the plant) normally react to inputs from humans and in this case, the operating staff.

According to Reason (1990), operators are there to cope with emergencies and that the greatest part of their experience in the control room is monitoring the plant and occasionally tweaking of the plant while it performs within safe operating limits. Reason (1990) affirms that an apparent solution would be for a large part of an operator's shift time to be spent in being coached in the diagnostic and recovery lessons of previous system emergencies. This instigates a Catch-22 situation. It is the nature of complex, tightly coupled, highly interactive, obscure and partially understood systems to be the cause of unpleasant surprises. Even if it were possible to build up an extensive repertoire of recovery routines, through simulations or game playing amongst operating crews, there is no guarantee that it would be relevant, other than in a very general sense, for some future 
event. As case studies show, incidents may begin in a conventional way, but they rarely proceed along predictable lines. Each incident is a truly novel event in which past experience counts for little and where the plant has to be restored by a mixture of good luck and laborious, resourcelimited and knowledge-based processing. Active errors in operation are inevitable. Whereas, in the more forgiving circumstances of everyday life where learning from one's mistakes is usually a beneficial process, in the control room of power plants, such educative experiences can have unacceptable consequences.

Reason (1990) found that the development of human reliability analysis (HRA) techniques has been intimately connected to the fortunes and misfortunes of the nuclear power industry. This does not mean that such methods are applicable only to the design and operation of nuclear power plants. They have been pioneered and widely used in other industries and organisations, but it is certainly true that nuclear power generation has been the focus of most human reliability developments over the past two decades.

The current level of knowledge resides predominantly with the Nuclear Power Industry, but basic principles can relate to a large degree to fossil generated power stations (coal-fired power stations). Literature, addressing human performance and concerned with safety and safe working conditions, is generally available.

Should human error be reduced or eliminated, the availability of production units could be improved substantially.

\section{Aim of the study}

The aim of this study was to determine the factors causing human error in the Generation Group of Eskom with the primary objective of determining into which human factor category human error falls. The secondary objective was to consider possible interventions for reducing/eliminating these errors.

Dhillon (1986) quotes that human error can be classified in various categories, of which the following are the best known:

- Operating errors (caused by operating personnel).

- Assembly errors (caused by humans during product assembly).

- Design errors (due to inadequate design).

- Inspection errors (associated with inspection to uncover defects).

- Installation errors (occurred during installations).

- Maintenance errors (due to incorrect repair of equipment).

Operating errors are identified as being errors made by operating personnel, which constitute the main causes of human error. The following situations lead to operating errors:

- Lack of proper procedures.

- Task complexity and overload conditions.

- Poor personnel selection and training.

- Operator carelessness and lack of interest.

- Poor environmental conditions.

- Departure from following the correct operating procedures.

The impact on the organisation is the loss of income for the period of non-production and any monetary savings that can be realised.

The problem statement claims that human error is responsible for a number of Unplanned Automatic Grid Separations (UAGS) on the electricity generation network of Eskom. UAGS cause loss of production.

Loss of revenue (income) causes unnecessary costs to be incurred in getting the units up to full production capacity again.
Trips can be caused by technical/mechanical failure, which is almost impossible to prevent. Factors causing human errors should be identified, grouped and addressed.

Electronic and/or written records of UAGS are available from the different power stations. The present drawback is that all the research that has been done on nuclear power stations focuses on human error being responsible for safety, and not on human error being responsible for production loss.

\section{METHOD}

\section{Research design}

The research design can be classified as exploratory/descriptive as it provides insight into the causal factors contributing to human error and also gives a description of the present situation.

\section{Target population}

The target population consisted of panel operators from the coal-fired power stations in the Generation Group of Eskom (approximately 700 panel operators). A haphazard sampling technique was followed. This is a non-probability sampling technique, whereby selection of the sample of participants was based on convenience, and which included individuals who were readily available. The sample represented $20 \%$ of the population and most power stations were represented. A sample size of 140 was used. Approximately $69 \%$ of the respondents were between the ages of 36 years and 50 years. The majority were married (about 90\%). All the respondents were males. The majority of the respondents $(95 \%)$ had passed matric/N3. The majority of the respondents $(62 \%)$ had between 6 years' and 15 years' service.

\section{Measuring instruments}

The instruments used were the monitoring of secondary records (data relating to production plant performance and investigation reports concerning trips), and personal face-to-face unstructured interviews (open-ended questions). The whole sample group (140) was interviewed. A questionnaire was also distributed to the sample group (140) and the response rate was $65 \%$. It was a field study, since it was conducted in the natural working environment. Information was obtained from interviews, questionnaires, and documented reports and records concerning the trip history of each station.

Based on the situations leading to operating errors as cited by Dhillon (1986), the human error factors were broken down and classified under the following causalities (factors) and the data from secondary records. Factors contributing to human error were collected, perused and allocated accordingly, as shown in Table 1:

TABle 1

HUMAN ERROR CASUALTIES

\begin{tabular}{|c|c|}
\hline Causality & Description \\
\hline Competency & $\begin{array}{l}\text { Knowledge of the job, skills and attitude } \\
\text { towards the job. }\end{array}$ \\
\hline Communication & The ability to express information. \\
\hline Procedural factors & $\begin{array}{l}\text { Clarity regarding standards and } \\
\text { procedures and whether they are adhered to. }\end{array}$ \\
\hline Mental and physical factors & Stress and cognitive overload and exhaustion. \\
\hline Socio-environmental factors & $\begin{array}{l}\text { Personal pressures such as family pressures and } \\
\text { organisational pressures such as work relations. }\end{array}$ \\
\hline Motivation & $\begin{array}{l}\text { Individual and organisational aspects like job } \\
\text { satisfaction and leadership style. }\end{array}$ \\
\hline Ergonomical factors & $\begin{array}{l}\text { Light, noise, space etc. this included health and } \\
\text { safety and shift cycles. }\end{array}$ \\
\hline
\end{tabular}


In order to correlate the findings, an organisational diagnostic questionnaire was given to the sampling group. The questionnaire that was used contained the CIQ human error classification with the addition of separate categories of Health and Safety, Equipment and Technology and Shift Cycles.

The Critical Incidents Questionnaire (CIQ) (Martens and de Koker) was used for this purpose, which consists of 85 items divided into 10 broad categories, namely:

TABLE 2

HUMan eRror CaUSALITIES (CIQ)

\begin{tabular}{ll}
\hline Causalities & Description \\
\hline Competency-based deficiencies & Knowledge, skill, attitude or behaviour \\
Communication-based deficiencies & Time lapse, expression \\
Motivational factors & Individual, organisational \\
Socio-environmental factors & Personal and organisational pressures \\
Ergonomics & Physical conditions \\
Procedural factors & Standards, procedures, documentation \\
Mental factors and physical & Emotional and cognitive over-load \\
Health and Safety & Employee health in work environment \\
Equipment and Technology & State of equipment and new technology \\
Current Shift System & Shift work \\
\hline
\end{tabular}

This CIQ was used to give the individual an opportunity to indicate how he feels regarding his present working situation and what factors contribute, in his opinion, to human error.

Interviews with the sampling group were conducted after completion of the CIQ, for clarification purposes, and to determine underlying contributors to certain factors like low morale.

\section{Statistical analysis}

Face to face interviews

Secondary records

- A history on trips caused by human error between 1998 and 2001 was compiled and scrutinised, yielding the results captured in Table 3.

TABLE 3

NUMBER OF TRIPS PER YEAR CAUSED BY HUMAN ERROR

\begin{tabular}{lllllll}
\hline Causal Factor & $\mathbf{1 9 9 8}$ & $\mathbf{1 9 9 9}$ & $\mathbf{2 0 0 0}$ & $\mathbf{2 0 0 1}$ & Total & $\%$ \\
\hline Competence & 14 & 16 & 17 & 14 & 61 & 31 \\
Communication & 6 & 13 & 1 & 7 & 22 & 12 \\
Procedural & 17 & 22 & 28 & 17 & 84 & 43 \\
Mental \& physical & 6 & 3 & 2 & 4 & 15 & 8 \\
Socio-environmental & 0 & 2 & 0 & 2 & 4 & 2 \\
Motivational & 2 & 1 & 0 & 3 & 6 & 3 \\
Ergonomical & 1 & 0 & 1 & 1 & 3 & 1 \\
\hline
\end{tabular}

Critical Incident Questionnaire (CIQ)

The CIQ was structured complying with the following intervals, and respondents completed the questionnaire accordingly.

- Intervals

$1=$ Differ strongly

$2=$ Differ

$3=$ Uncertain

$4=$ Agree

$5=$ Agree strongly
The observations made in this research reflect interpretation of the data based on statistical analyses as represented by Huysamen (1983). For this research project, the benchmark used was a mean value of 3,5 . Mean values of 3,4 or less of the trips caused by human error, were treated as possible problem areas. The results are presented in Table 4 .

TABLE 4

RESULTS OF TRIPS CAUSED BY HUMAN ERROR

\begin{tabular}{lccc}
\hline Item & Mean & Standard deviation & $\mathrm{N}$ \\
\hline Knowledge & 3,480 & 0,9788 & 140 \\
Skills & 3,360 & 0,9598 & 140 \\
Attitude/behaviour & 3,100 & 1,0172 & 140 \\
Communication & 3,605 & 0,6690 & 140 \\
$\begin{array}{l}\text { Motivational Factors } \\
\text { (Individual) }\end{array}$ & 3,1143 & 0,8335 & 140 \\
Motivational Factors & 3,2314 & 0,6999 & \\
(Organisational) & & & 140 \\
Organisational Pressure & 3,1229 & 0,6454 & 140 \\
Personal Pressure & 3,3371 & 0,9169 & 140 \\
Social Issues & 3,5286 & 0,6854 & 140 \\
Physical conditions & 3,7829 & 0,5716 & 140 \\
Procedural factors & 3,8400 & 0,5558 & 140 \\
Mental factors & 3,4857 & 0,7068 & 140 \\
Physical factors & 3,8186 & 0,6651 & 140 \\
Shift system & 3,2957 & 0,6757 & 140 \\
Health and Safety & 4,0686 & 0,5161 & 140 \\
Equipment & 3,8829 & 0,7081 & 140 \\
\hline
\end{tabular}

According to Christensen (1997) the size of the standard deviation is important because it gives an idea of the group mean differences, as well as indicating the accuracy of the sample. The smaller the standard deviation, the more confident one can be that the sample represents the population.

\section{RESULTS}

Interpretation of findings

It is important to note that the failure to follow stated procedures is sometimes due to procedures that are too lengthy, too slow or too fast. The value of the study captured important knowledge regarding factors causing human error, which results in production loss. Trends are determined and proactive event management can be introduced in order to reduce, and ultimately eliminate, human error as a cause for production loss.

A discrepancy was found between the points of departure of the secondary records and the CIQ regarding procedural factors. The latter refers to the availability of procedures for doing the job, whilst the former refers to adherence to the available procedures. This relates to operating personnel not adhering to the procedures and therefore causing a trip. The face-to-face interviews confirmed the discrepancy.

Findings from the secondary records are that procedural problems and incompetence are the main factors for humanrelated trips:

- $31 \%$ of trips ascribed to human error are caused by incompetence.

- $43 \%$ of trips ascribed human error are caused by nonadherence to procedures. 
The findings of the research done on human error, clearly indicate that the lack of competence in operating the panels and the plant, as well as the tendency to ignore standard instructions, are the main causalities of human error. It was gleaned from the interviews that the tendency to look for shortcuts or to disregard procedures could be attributed to low motivation and attitudinal problems of the employees. According to the results from the CIQ, individual and organisational motivational factors, organisational pressures and attitude are the predominant problem areas. Motivational factors encapsulate recognition for performance and efforts, objective performance management and the remuneration system. Attitude comprises the attitude towards work and the motivation to apply skills; and organisational pressure encapsulates job satisfaction, conflict management and job load.

Respondents completing the CIQ gave an opinion regarding the availability and quality of procedures.

\section{Lack of competence and non-adherence to procedures}

According to the respondents, $74 \%$ of human error could be eliminated if the organisation concentrates on the lack of competence and non-adherence to procedures (caused by low motivation and bad attitude towards work, or even boredom). For the purpose of this research project, all the human error categories are addressed. Reason (1990) cites Rasmussen (1980) and INPO (1984), stating that research indicates that simple omissions, and the failure to carry out some of the actions necessary to achieve a desired goal, constitute the single largest category of human performance problems identified in significant event reports logged.

Research done by Meister (1962) supports the above findings and the author writes that inadequate training and poor motivation entices human error.

According to Dhillon (1986), operator carelessness and lack of interest (low individual motivation and bad attitude towards work) also contribute to human error. The same author writes that departing from correct operating procedures contributes significantly towards human error, and that the mismatch between worker and job and poor attitude are also indirect causes of incidents. This supported investigations that low motivation, organisational pressures and a negative attitude towards the work can result in operating personnel disregarding operating procedures and causing errors, contributing directly to the high percentage of human-error trips caused by procedural factors.

\section{Competence}

Competence is the other main causality. A concern derived from the interviews was that the competence of certain panel operators was not at the required levels. A major causality was the accelerated development programme followed in training new learners. The result of this was employees without the necessary knowledge, competence or skills being promoted to panel operators. During crisis situations, these deficiencies surface and the panel operators often make the wrong decision or just do not know what to do to prevent a trip.

A void in the research was that some factors, such as the socioenvironmental factors, could be omitted by respondents, since very few (if any) of the operators responsible for a human-errorrelated trip would acknowledge that they had socioenvironmental problems. The negative connotation attached to alcoholism, marital or psychological problems prompt people to try and hide such causalities.

\section{Month-of-the-year trip}

This refers to the month of the year when most trips occur. Most trips occur in the first and last quarters of a year, which could indicate that towards the end of the year personnel are inclined to lose focus, and at the beginning of the year they could still be somewhat relaxed. There is, however, no empirical evidence to confirm this statement.

\section{Time-of-the-day of trips}

This refers to the time when trips mostly occur. From the data collected, the time of day for trips is categorised as being between 03:00 to 07:00; 07:00 to 12:00; $12: 00$ to $17: 00 ; 17: 00$ to 22:00; and 22:00 to 03:00. This was done in order to accommodate shift changes and to determine whether the time of the day has any significant effect. The percentage of humanerror trips occurred as follows:

TABLE 5

Percentage of human error trips during TIMe Period

\begin{tabular}{lll}
\hline First period & 03:00 to $07: 00$ & $23 \%$ \\
Second period & $07: 00$ to $12: 00$ & $25 \%$ \\
Third period & $12: 00$ to $17: 00$ & $23 \%$ \\
Fourth period & $17: 00$ to $22: 00$ & $17 \%$ \\
Fifth period & $22: 00$ to $03: 00$ & $12 \%$ \\
\hline
\end{tabular}

No significant trend could be established, other than that $71 \%$ of human-error- related trips occur between 03:00 and 17:00.

Studies done by Carpentier and Cazamian (1978) for the International Labour Office cite that it has been found that, among workers regularly employed on night work, there was an increase in motor reaction time and a decline in performance for spoken word tests, with maxima at 03:00. The authors write that similar test results have been obtained from the speed of response to an experimental test and from the flicker-fusion threshold. Faulty responses in an experimental task are especially frequent between 04:00 and 06:00, when the speed of response and the detection-of-signals rate are hardly affected. These are the primary sensory functions used when operators must sometimes make decisions within a split second. This supports the findings that there is no significant deviation from the trip records during the early morning hours.

\section{Ergonomics}

\section{Health and Safety}

From the research it was determined that health and safety factors did not contribute to human error and no human-error trip could be related back to non-conformance regarding the Occupational Health and Safety Act (Act 85 of 1993).

Eskom Power Stations adhere to the Environmental Regulations for Workplaces, as well as the Facilities Regulations applicable under Act 85 of 1993.

Regarding environmental regulations the lighting, ventilation and housekeeping comply with, and exceed, the requirements. Regarding the facilities regulations, Eskom also complies with the requirements for sanitation, safekeeping, change-rooms, seats (chairs) and drinking water for the (shift) workers. The human-error trips due to ergonomic reasons refer to the lay-out of the operating panels, where operators were distracted and the labeling of switches was confusing, for example where open and close switches are less than $10 \mathrm{~mm}$ apart and the labels encompass both switches.

\section{Shift cycles}

Studies done by Carpentier and Cazamian (1978) found that night work causes fatigue and in many cases a psychosomatic occupational disorder. The mental load involved in a task and the ageing of a worker can constitute aggravating circumstances. Night work also disturbs family and social life. 
According to Kroemer and Grandjean (2000), assumptions were made that night work would be conducive to lower output and more frequent incidents. Although statistics were gathered, the facts did not clearly support the hypothesis. In some cases the incident rate at night seems hardly altered, or even reduced. The authors write that this contradiction between theory and practice reflects the conditions surrounding the night worker, such as fewer disturbances from other people, higher wages, different kinds of work and so on, compared with the circumstances of day work. This supports the findings that no trend can be determined that night work is a causality of human error within the operating fraternity in power stations.

\section{Mental and Physical Factors}

According to the summary of the history on trips caused by human error, mental and physical factors contribute only $8 \%$ to causalities. Boredom can have a major influence on the mental state of an employee and could also contribute to disregarding procedural guidelines. Kroemer and Grandjean (2000) reached the conclusion that personal factors have a considerable impact on the incidence of boredom, or on the ability to withstand boredom. The authors write that proneness to boredom is higher for, amongst others, the following people:

People with low motivation and little interest can resort to nonadherence of procedures.

According to Kroemer and Grandjean (2000), one could distinguish between boredom itself and its emotional manifestations, which the authors call satiation. This refers to a state of irritation and aversion to activity, which promotes boredom. A person feels that she/he has had enough. This is a state of actual conflict between a feeling of duty to work and the desire to have done with it, which puts the person involved under increasing internal tension.

\section{Occupational stressors}

Dhillon (1986) affirms that stress plays a major role in affecting human performance. The author writes that it is obvious when an operator is performing a task under extreme stress, and the probability of the occurrence of human error will be higher than when he or she is operating under moderate stress.

Occupational stressors can be classified into the following four types:

- Type 1 . This concerns work over-load or work under-load and examples of under-load are lack of intellectual input and repetitive performance.

- Type 2. This involves occupational change such as reorganisation and relocation.

- Type 3. This is concerned with problems of occupational frustration, which results in situations where the job inhibits the meeting of set goals, lack of communication, poor career development and bureaucracy difficulties.

- Type 4. This is associated with other possible sources such as ergonomics and poor relationships.

According to the same author, the following factors induce stress in the human operator:

1. Information feedback to the operator is inadequate for determining the correctness of his or her actions.

2. Comparisons needing to be made between two or more displays quickly.

3. Decision-making time is very short.

4. Prolonged monitoring by the operator.

5. To perform a task, the sequence of steps to be followed is very long.

6. More than one display is cumbersome to differentiate.

7. A requirement to operate more than one control simultaneously at high speed.

8. Performing operating steps at high speed.

9. Decisions that have to be made on the basis of data collected from various sources.
From the interviews with the target group, it was established that the following were the main contributors to high stress levels and affected the operator's mental ability to cope with the given situation:

- Comparisons needing to be made between two or more displays quickly.

- Decision-making time is very short.

- The sequence of steps needed is very long.

- Operating more than one control simultaneously at high speed.

- Perform operating steps at high speed.

Adding to the above, Dhillon (1986) confirms that the following factors aggravate stress in operators:

1. Having to work with people who have unpredictable temperaments.

2. Unhappy with the present job.

3. Financial difficulties.

4. Having problems with family.

5. Poor chances for promotion at work.

6. Possibility of redundancy at work.

7. Lacking the expertise to perform the job.

8. Poor health.

9. Performing under extremely tight time pressures.

10.Having a job below one's ability and experience.

11. Excessive demands from superiors at work.

From the interviews with the target group, the following factors contribute towards increased stress levels:

- Poor chances of promotion at work.

- Possibility of redundancy at work.

- Having a job below one's ability and experience.

- Excessive demands from superiors at work.

Many competent white male panel operators see no further promotional possibilities for them, although they still have 20 to 25 years' service left. This is due to the Employment Equity drive of Eskom. Because of their restricted field of expertise, work opportunities outside Eskom are limited.

For the same Employment Equity reason, black operators are promoted prematurely and often lack the expertise to perform on the job. White supervisors are inclined to put excessive demands on these operators and, during a crisis situation, they are prone to human error.

\section{Communication}

Communication problems contributed $13 \%$ towards the causalities of human error

Associated with this is face-to-face communication and feedback as well as communication by radio/telephone etc. From the interviews it was determined that communication broke down when employees were instructed to perform certain operational tasks. In a crisis situation the message that is transferred is not understood due to mental blockage processes, such as preconceived ideas about what could be wrong. An example is when the water flow in the cooling system is interrupted, a faulty valve is perceived to be the cause, but it could be that the labelling of the display on the panel is incorrect, thus indicating that the valve is open while actually being closed. The noise level also plays a role when communicating by radio. Sometimes instructions are not clearly heard. The last aspect is the lack of constant feedback from line managers regarding performance.

\section{Summary}

A major factor of human error is an incompetent panel operator. Accelerated development and learning programmes contribute to this situation due to operators being promoted prematurely. Other contributing factors are low motivation, because of limited promotional opportunities, organisational pressure due to excessive demands by superiors and negative attitudes. This creates the tendency to ignore procedural requirements. 
Occupational stressors are also causalities, albeit not major.

Should these causalities be addressed, factors causing human error could be reduced by as much as $70 \%$.

\section{SUGGESTIONS AND RECOMMENDATIONS (DISCUSSION)}

According to Dhillon (1986), there are certain methods/ interventions that one could introduce to prevent human error.

The first method deals with characteristics such as motivation, competence and adherence to procedure problems.

This method is known as man-machine system analysis, which can be used to reduce unwanted effects caused by human error to some acceptable level in a system. This method comprises 10 steps as shown below.

\section{TABLE 6}

\section{MAN-MACHINE SYSTEM ANALYSIS}

\begin{tabular}{ll}
\hline Step 1 & Outline the functions and goals of the system. \\
Step 2 & $\begin{array}{l}\text { Outline the situational characteristics subject to which humans } \\
\text { will have to carry out tasks such as union activities. }\end{array}$ \\
Step 3 & $\begin{array}{l}\text { Outline the characteristics of manpower associated with the } \\
\text { system. Identify and estimate the characteristics such as } \\
\text { training required to improve competence, experience, } \\
\text { motivation and skills levels. }\end{array}$ \\
Step 4 & $\begin{array}{l}\text { Outline the tasks and jobs carried out by the system manpower. } \\
\text { Step } 5\end{array}$ \\
Step 6 & $\begin{array}{l}\text { Orform analysis of tasks and jobs to raise potential "error- } \\
\text { likely" conditions and other associated difficulties. }\end{array}$ \\
Step 7 & $\begin{array}{l}\text { Obtain an estimate for the likelihood that each potential error } \\
\text { will remain undetected and uncorrected. }\end{array}$ \\
Step 8 & $\begin{array}{l}\text { Obtain an estimate for the consequences of each undetected } \\
\text { potential error. }\end{array}$ \\
Step 9 & $\begin{array}{l}\text { Make recommendations for changes to the system. } \\
\text { Step } 10\end{array} \quad \begin{array}{l}\text { Re-evaluate each system change by repeating most of the above } \\
\text { nine steps. }\end{array}$
\end{tabular}

Step no 3 (identifying characteristics requiring improvement) is critically important if management is determined to eliminate factors causing human-error trips, and this will address about $80 \%$ of the causalities of human error.

\section{Improved job satisfaction}

In addition to the identification of characteristics required to improve, the organisation could follow a method that Swain (1973) calls an error-cause removal program (ECRP). The emphasis here falls on preventative measures rather than on remedial ones. The method is useful in the sense that it can improve job satisfaction of workers, because it requires their direct involvement and participation. This should have a direct impact on reducing human error.

Workers were directly involved in the data collection, analysis and design recommendation aspects. This created a sense of ownership. Each ECRP was composed of teams of operating personnel, who had a coordinator whose responsibility was to keep the team focused and goal-driven.

In periodic error-cause-removal team meetings, reports of the error and "error- likely" situations were examined and discussed. Suggestions for remedial or preventative actions were made. This was then presented to management for action. Human resources and other specialists could assist each team, as well as management. These specialists helped both parties with respect to evaluation and implementation of the suggested design solutions. Implementation of such solutions should prevent human error.

Important guidelines:

- The data collection should be concerned with error-likely situations and errors.

- The programme should be restricted to the identification of work conditions that need to be redesigned to reduce error potential.

- A team of specialists should evaluate each redesigning of the work situation.

- Error-cause-removal program components.

- Management should implement the most appropriate design solutions.

- Efforts by employees are recognised by management.

- The errors and "error-likely" situations are reported and their causes determined.

Reason (1990) lists the following Human Reliability Analysis Methods/Techniques, which should contribute towards achieving the goal of reducing human-error related trips.

Probalistic risk assessment (PRA)

PRA aims to identify potential areas of risk, indicating how improvements can be made, and to quantify the overall risk of a potentially hazardous plant. PRA's are logical "tree" models of the plant and its functions and assume two basic forms, namely: fault trees that address the question of how a given plant failure occurs and event trees that answer the question of what could happen

Technique for human error rate prediction (THERP) THERP provides human reliability data for PRA studies.

THERP assumes that the operators' actions can be regarded in the same light as the success or failure of a given pump or valve. Operator activities are broken down into task elements and substituted for equipment outputs in a more or less conventional reliability assessment, with adjustments to allow for the greater variability and interdependence of human performance. As such, the reliability of the operator can be assessed in essentially the same way as an equipment item.

Empirical technique to estimate operator errors (TESEO) TESEO yields the probability of operator techniques through the combined application of five error probability parameters, K1 to K5. It is a mathematical model that can quantify human reliability in specific process situations. The parameters refer as follows:

$\mathrm{K} 1$ = type of activity

$\mathrm{K} 2=$ temporary stress factor for routine activities

$\mathrm{K} 3=$ operator qualities

$\mathrm{K} 4=$ an activity anxiety factor

K5 = an activity ergonomic factor

Dhillon (1986) lists the following techniques:

The author also refers to THERP.

\section{The Probability Tree Method}

This technique is concerned with representing critical human actions and other events associated with the system under consideration. Diagrammatic task analysis is represented by the branches of the probability tree and represents outcomes (i.e. success or failure) of each event. Each branch of the tree is assigned an occurrence probability.

Pontecorvo's Method of Predicting Human Reliability This method is concerned with obtaining estimates of reliability of separate and discrete subtasks having no correct reliability figures. This method accesses the interaction of men and machines quantitatively. In addition, it determines the performance of a single person. 
Rooks Model of Human Error Occurrence

This model can be used to compute the total probability of no function failures over all independent types of tasks. This is also a mathematical model that is used in situations where system failures result from errors committed in repetitive manual assembly work.

It was also experienced that a combination of factors plays a role in a crisis situation. According to Dhillon (1986), in order to minimise the occurrence of human errors, the design engineer and the reliability engineer must consider operator limitations or characteristics during the design phase. Proper training and management principles could, however, also contribute significantly towards eliminating these characteristics and factors.

\section{Strategies aimed at changing the environment}

This strategy will address socio-environmental factors.

Newman and Beehr (1979) cite Levi (1967) in claiming that the Government and Society in general ought to make some changes in the overall environment. He suggests a reshaping of Society in a more humane direction. This strategy could involve a comprehensive, long-term social programme designed to provide psychological security as a complement to economic security. This programme would be aimed at the institutions of marriage, family, child-care, education and work. The organisation's Social Responsibility Programme would help to improve environmental circumstances and would alleviate socio-environmental stressors.

\section{Organisational strategies aimed at changing organisational processes and the environment}

This strategy would address job enlargement, boredom and proper human resource allocation, which would affect organisational pressures as well. Employees would experience higher levels of job satisfaction.

According to Newman and Beehr (1979) a group of researchers conceptualised job-stress problems as one of person-work environment misfit. Therefore, their meta-strategy for handling stress is aimed at maximising the fit between the person and the work environment. They point out that stress management does not involve the total elimination of all stresses in organisational life, but rather it implies reducing stress to levels commensurate with the tolerance and needs of individuals. The authors use an example of an organisational diagnosis, which reveals that certain stressful jobs are characterised by low responsibility for other people, under-utilisation of one's skills and ability, low participation, insecurity and ambiguity with respect to one's occupational future. One could address these stresses through programmes of job enlargement, job enrichment and increased participation.

The types of job stressors must be identified, as well as the extent to which they are related to the state of employees' health and motivation. This diagnostic information should be utilised in the design of programmes of prevention and therapy. It should also take into account individual differences and specifically consider the problems of changing the environment to fit the person and changing the person to fit the environment.

The only two parties who can make a difference regarding mental stress factors are management and the worker. Management could ensure that they do all that they can to eliminate contributing factors and the worker himself should work on coping strategies for those stressors that cannot be changed e.g. the employment equity legislation implemented by the government.

According to Reason (1990), the decision-makers, high-level managers, of a system should direct the goals at strategic level. A large part of their function is to allocate finite resources, comprising money, equipment, people (talent and expertise) and time to deploy these resources for maximising productivity. Supporting this strategic direction are the line managers who are responsible for implementing these directives.

Appropriate decisions are not themselves sufficient. Something is needed between the line managers and productive activities. These are a set of qualities, possessed by both machines and people, and are: reliable equipment of the right kind; a skilled and knowledgeable workforce; work schedules, maintenance programmes and environmental conditions that permit efficient and safe operations; codes of practice that give clear guidance regarding desirable and undesirable performance and an appropriate set of attitudes and motivators.

Where productive activities involve exposure to natural or intrinsic hazards, both the individuals and the machines should be supplied with safeguards, sufficient to prevent foreseeable injury, damage or costly outages.

The author also states that many of the above factors are influenced by decisions made by top and middle management. Management style can also influence attitudes and motivation. Should they make the wrong decisions regarding the above matters, it could have an adverse effect on employees.

If there are problems concerning some of the mentioned factors, it is possible for management to influence it positively by a specific intervention, e.g. state-of-the-art training, improved working schedules and enhanced environment.

Reason (1990) states that: The innate incompetence of any set of line managers could further exacerbate the adverse effects of high-level decisions or even cause good decisions to have bad effects. Conversely, competence at the line management level could mitigate the inefficient impact of fallible decisions, or make neutral decisions, having more efficient consequences and transforming good decisions into even better ones.

It is recommended that line managers should be developed towards being competent in fulfilling their responsibilities. Attitude towards their subordinates should foster trust and commitment. This behaviour will influence attitudes and motivation of the subordinates positively. Management is also responsible for ensuring that the workforce is skilled and knowledgeable in order to perform at optimal levels.

Westrum (1988) has provided a simple but meaningful classification of the ways in which organisations may differ in their reactions to safety data. His basic premise is that organisations think. Like individuals, they exhibit a consciousness, a memory and an ability to create and to solve problems. Their thinking strongly reflects the generation and elimination of hazards. Organisational responses to hazards fall into three groups: denial, repair and reform actions. The more effective the organisation, the more likely it is to respond to safety data with actions from "reform," while those less adequate will employ responses from "denial." Westrum (1988) then uses these reactions to define organisations along a scale of what he calls "cognitive adequacy", or the effectiveness in their ways of thinking about hazards. These are grouped under three headings: pathological, calculative and generative organisations and can be applied to the management style of an organisation.

\section{Pathological organisations}

Pathological organisations are ones whose safety measures are inadequate even under normal conditions. These organisations sacrifice safety goals in the pursuit of production goals, often under severe economic pressures, and actively circumvent safety regulations. Information about hazardous conditions is suppressed at the source by censoring or restraining the messenger. 


\section{Calculative organisations}

Calculative organisations try to do the best job they can by using "by-the-book" methods. These are usually adequate under normal operating conditions, but often fail when they encounter unforeseen circumstances. In short, they may implement many safety practices, but have little in the way of effective disaster plans.

\section{Generative organisations}

Generative organisations are charactarised by a high degree of ostensibly irregular or unconventional activities in furthering their goals. They set targets for themselves beyond ordinary expectations and fulfil them because they are willing to do unexpected things in unexpected ways. They emphasise results rather than methods and value substance more than form. Hazards tend to be quickly discovered and neutralised because lower-level personnel have both the freedom to see and permission to do.

This "cognitive adequacy" can be applied to human error incidents as well.

The organisation's management style falls into the calculative category.

To improve, the organisation's leadership can "move" the organisation to be more generative, by setting tough, but achievable targets. The emphasis on results could be achieved by means of a proper performance management system.

Empowerment of lower level employees would ensure that defects are detected and dealt with at an early stage. Empowered employees would experience more job satisfaction, which would contribute to better motivation and more positive attitudes. Ultimately this would reduce the possibilities of human error.

Communication forms part of establishing a culture in an organisation and has been dealt with in the discussions above. It is imperative though, that management ensures that electronic and verbal communication channels are properly used.

It should be added that feedback also plays a major role in the process of influencing attitude and motivation. Drury and Fox (1975) write that in most work situations line managers do not adequately describe what people should do, and almost never give subordinates feedback. The authors cite Henry Parsons (1974) where he argues persuasively in an article that the noted Hawthorne Effect was really a feedback effect. Performance kept improving in the now famous Hawthorn studies, despite variations in working conditions, because workers knew exactly how they were performing and it improved performance.

Drury and Fox (1975) say that: If management is serious about such things as improving performance or improving worker satisfaction, they should be developing ways to provide consistent and reliable feedback. Each worker should know how well she/he is doing and what he or she is contributing. Management does not do much of this because it is not an easy thing to do, but this is another of those things that line managers should be working on and there is lots of room for improvement. The fact that feedback is difficult for one job is no excuse for not providing good feedback on other jobs where it is less difficult.

The research proved that factors leading to human error could be reduced, or even eliminated, but the responsibility to implement proposals lies with management. If they are committed to implement these proposals, plant performance could be improved substantially.

\section{REFERENCES}

Carpentier, J. \& Cazamian, P. (1977). Night Work. International Labour Organisation. Geneve Switzerland

Christensen, L.B. (1997). Experimental Methodology (7 th edition). Boston: Allyn \& Bacon.

Dhillon, B.S. (1986). Human Reliability with human factors. New York USA: Perganon Press.

Drury, C.G. \& Fox J.G. (1975). Human Reliability in quality control. London: Taylor \& Francis Ltd.

Kroemer, K.H.E. \& Grandjean, E. (2000). Fitting the Task to the Human (5 th edition). A Textbook of Occupational Ergonomics. UK: Taylor \& Francis Ltd.

Meister, D. (1962). The Problem of Human-initiated Failures. Proceedings of the Eigth National Symposium on Reliability and Quality Control. IEEEE: New York.

Mager, R.F. \& Pipe, P. (1992). Analyzing Performance Problems. Wiley: London.

Newman, .JE. \& Beehr, T.A. (1979). Personal and Organizational Strategies for Handling Job Stress: A review of Research and Opinion. Personnel Psychology, 32.

Occupational Health and Safety Act. (No 85 of 1993).

Reason, J.T. (1990). Human Error. Wiley: London.

Westrum, R. (1988). Organizational and inter-organizational thought. In World Bank Workshop on Safety Control and Risk Management. Washington. 